\title{
Overviewing Quality of Electric Vehicle Charging Stations' Service Evaluation
}

\author{
Tohid Harighi*, Ramazan Bayindir*, Eklas Hossain** \\ *Gazi University, Faculty of Technology, Department of Electrical \& Electronics Engineering 06500, Ankara/TURKEY \\ **Oregon Tech, Department of Electrical and Renewable Energy, OR-97601, USA \\ (Tohidharighi@gmail.com, bayindir@gazi.edu.tr, eklas.hossian@oit.edu)
}

Received: 26.02.2018 Accepted:10.03.2018

\begin{abstract}
Worldwide greenhouse gas emission is increasing rapidly in twenty-first century, and one of the main reasons of this upsurge is emission from internal combustion engine (ICE) cars. A major step to decrease greenhouse gas emission can be replacing ICE cars with electric vehicles (EV). Though the EVs have notable benefits such as lower GHG emission, their effects can both be good and bad, depending on certain conditions. EVs have impact on the power grid, and associated equipment. In this paper, few key concerns about the grid infrastructure related to EV connections are illustrated, with focus on grid-scale storage systems. Environmental factors and budget considerations for EV charging stations are also discussed, with evaluations of the findings through MATLAB/Simulink simulations.
\end{abstract}

Keywords: Electric vehicles, Energy conversion, Power systems, Terrain, Grid connected storage systems, Transportation, Renewable energy sources.

\section{Abbreviation}

$\begin{array}{ll}B & \text { Building } \\ B O & \text { Boiler } \\ C S & \text { Charging Station } \\ G & \text { Power Grid } \\ P G U & \text { Power Generation Unit } \\ \eta_{c} & \text { Charging Efficiency } \\ \eta_{\text {etoc }} & \text { Electricity-to-Carbon Conversion Factor } \\ \eta_{f t o c} & \text { Fuel-to-Carbon Conversion Factor } \\ C & \text { Cost Function } \\ C_{t a x} & \text { Carbon Emission Tax } \\ E L & \text { Building Electric Load } \\ P F & \text { Fuel Price } \\ P P & \text { Electricity Purchasing Price } \\ P S & \text { Electricity Selling Price } \\ e & \text { Stored or Generated Electricity } \\ e c & \text { Electricity Charging Rate } \\ e f_{A . B} & \text { Electricity Flow from A to B } \\ f & \text { Fuel Consumption }\end{array}$

\section{Introduction}

Today, electric vehicles (EV) are an important part of the transportation system in the world [1]. Because of that, $\mathrm{CO}_{2}$ emissions are expected to decrease while the efficiency of energy use will be high. For example, the combined heat and power (CHP) efficiency may be $42 \sim 75 \%$ [2]. Behind the scenes, there should be powerful and bidirectional grids, which are powered by fossil fuel or renewable energy generators. Fig 1 gives grid and supply/demand circle in operation. The grids not only should support EV fleets but also other demands. EVs are not usually supplied in most of the electric networks. So electric vehicle fleet system is a new technology and it can not be predicted in advance. Today, in order to supply EVs, the grid needs a "plan B" to develop, and increase the capacity [3]. Therefore population density, the infrastructure of grid, the source of energy, habitude of using fleet and some other aspects are perks of the grid development [4]. Replacement of vehicle fleet is necessary and this program has turned out as a legislation in EU [5]. At first sight, it seems like there is a controlling issue, but it is a different deal altogether. For example, regular control problems could be solved with Laplace block diagram node or some other mathematical nodes. In this problem of management program of the grid, there are three parts to be solved to support EVs [6]. Fig 2 illustrates supply/demand division in the grid. 


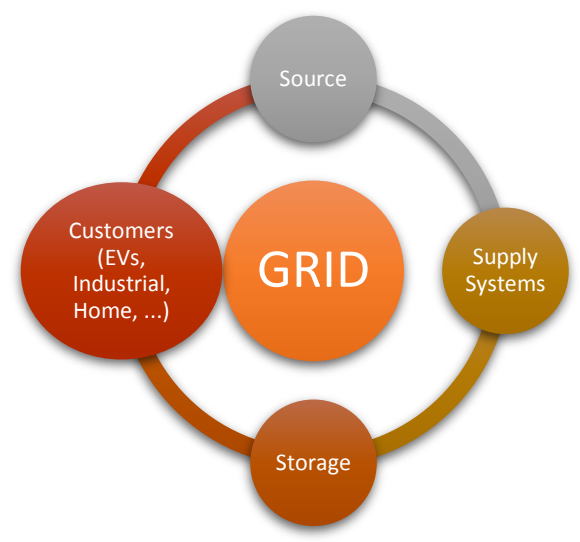

Fig 1: Grid and supply/demand circle, EVs and other customers represent the demand side.

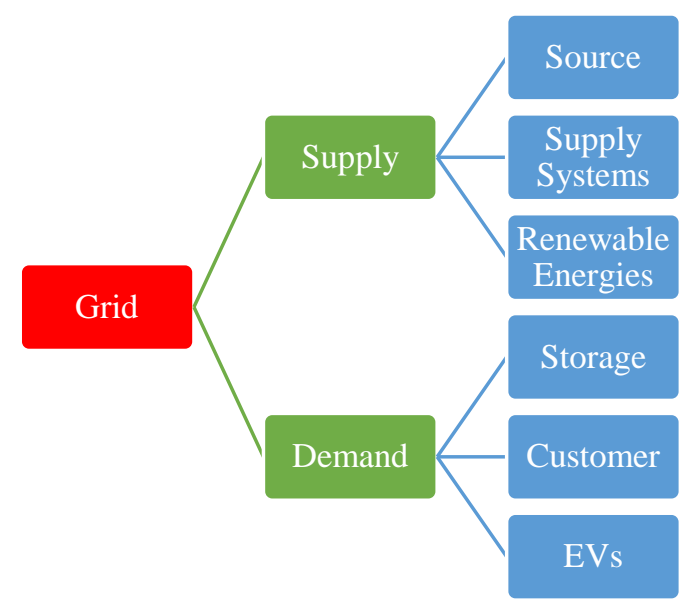

Fig 2: Division of supply and demand in a grid, supply can come from a number of sources, and the demand is diverse.

Other nodes of the systems have control parameters, such as peak time. But the other parameters and alternatives of nodes can improve or deteriorate EV charging stations. Charging stations are the points which can transmit power from the grid to the EVs [7]. Determining locations of the charging stations may lead to severe problems in an electric network such as problems in low voltage and high voltage infrastructure [8]. In some countries, urban growth is very fast, but the supply side may only support the regular consumption; so the EV charging station will need a stable and powerful grid to work with peak and off-peak loads (EV charging during off-peak hours and discharging in peak hours). In this situation, the grid cannot respond to charging stations citywide. It does not mean that the grids with low capacity cannot support EV charging stations and electric fleet systems; it means that the electric fleet systems without required background are useless $[9,10,11]$. This paper describes some hidden threats in the grid and what will happen when EVs connect to the grid in large scale.

The rest of the paper is organized as follows: section III illustrates on the infrastructural requirements EV charging stations, section IV presents required supply system and policy outlines, an overview of suitable storage techniques is presented in section $\mathrm{V}$, section VI summarizes the environmental factors, section VII shows the budget considerations, section VIII validates the findings through MALAB simulations, while section IX draws the conclusion.

\section{Infrastructure}

The base of a system must be in a good shape when it gets updated, therefore there must be high-quality power on both sides (generation and distribution) of the grid [12, 13]. The power-capacity of the grid and the quality of the power are both necessary factors. Based on these factors the grid should be smart and micro (micro grid/smart grid) [14]. The power line should not follow just AC system; as the renewable energy sources (RES), electric fleet systems, and some other systems use DC. None of the converters work properly with AC and they cause side effects such as harmonics [15]. Thus the grid must support both AC and DC types of energy. Some generators can be connected to grid with DC terminals such as solar and wind energy systems. DC energy can easily be harvested with EVs through charging stations too [16, 17]. Recycling of energy by EVs and some storage systems take place through bi-directional terminals, so it is a key point in modern grid systems [18]. In these situations, grid behavior is very flexible [19]. The DC converters have high-quality and efficient conversion capabilities; with those converters, the customer can use energy in both high and low potentials [20]. The charging system in any location can be a fast charger or a regular one, depending on the customer base, and as the grid infrastructure allows [19, 20, 21, 22, 23]. Power injection by solar or wind energy could be executed in all locations of the grid if it has DC systems because DC power line provides a wide range of options for direct supply and demand connections [21]. Low quantity of converters is the goal in all electric networks. They have a loss in the base topology, which cannot be avoided. For example, in this study, the switching loss is calculated by [24]:

$$
\begin{gathered}
w_{\text {Toff }}=K_{\text {Toff } 1} u i+K_{\text {Toff } 2} u i^{2}+K_{\text {Toff } 3} u^{2}+K_{\text {Toff } 4} u^{2} i \\
+K_{\text {Toff } 5} u^{2} i^{2}=w_{\text {Toff }}(u . i) \\
w_{\text {Ton }}=K_{\text {Ton } 1} u i+K_{\text {Ton } 2} u i^{2}+K_{\text {Ton } 3} u^{2}+K_{\text {Ton } 4} u^{2} i \\
+K_{\text {Ton } 5} u^{2} i^{2}=w_{\text {Ton }}(u . i) \\
w_{\text {Don }}=K_{\text {Don } 1} u i+K_{\text {Don } 2} u i^{2}+K_{\text {Don } 3} u^{2}+K_{\text {Don } 4} u^{2} i \\
+K_{\text {Don } 5} u^{2} i^{2}=w_{\text {Don }}(u . i)
\end{gathered}
$$

Where $u$ is voltage; $i$ is current; $T$ is related to the IGBT duty cycle, $\mathrm{D}$ is related to diode, and $K i$ is IGBT switching loss parameters.

On the other side of the charging station efficiency, the building efficiency is very important. In this study, the system has combined cooling, heating \& power (CCHP), photovoltaic (PV) generation, and building heating and cooling system. Calculation of energy cost and the result of the cost give operation status [25]: 
T. Harighi et al. ,Vol. 2, No. 1, March, 2018

$$
\begin{aligned}
& C_{B}= \sum_{t}\left(e f_{G . B . t} \times P P_{t}-e f_{B . G . t} \times P S_{t}\right) \\
&+\sum_{t} e f_{G . B . t} \times \eta_{e t o c} \times C_{t a x} \\
&+\sum_{t}^{t}\left(f_{P G U . t} \times P F_{t}+f_{P G U . t} \times \eta_{f t o c} \times C_{t a x}\right) \\
&+\sum_{t}^{t}\left(f_{B O, t} \times P F_{t}+f_{B O, t} \times \eta_{f t o c} \times C_{t a x}\right) \\
&+\sum_{t}\left(e f_{C S, B, t} \times P T_{t}-e f_{B, C S, t}\right. \\
&\left.\times P T_{t}\right)
\end{aligned}
$$

Finally, grid infrastructure should be powerful, bi-directional, flexible and suitable to make DC power line provide highquality electricity while protecting the grid.

\section{Supply}

The supply side of the grid is a special issue. Energy generation and transmission have different problems. In some situations, the grid has enough power but it cannot provide power to the customers because of not having suitable transmission system [22]. The reverse is also true. Fast charge system is much more usable mostly in city centers [26, 27]. In this situation, the energy policy is very important. Energy policies have to be adjusted according to future prospects. Currently, city centers have a huge electric load. As of now, energy companies should support the power and equipment requirements of EV charging stations. Energy consumption in general view and from Electrical Engineering perspectives are very different. People think of energy as fossil fuel, atomic energy, or renewable energies; but electrical engineers define energy as all the things that can generate electricity [28]. So, if a politician proposes a policy without considering the technical side of the issue, it can cause major problems. City centers' electricity supplies need a grid with different energy sources and terminals with enough power, which is a way to solve location problem [29, 30, 31]. Supply and demand relation should be equal in every instant. For example, in case 2 , load balance is [25]:

$$
\begin{aligned}
& \quad e f_{G, B, t}+e_{B P V, t}+e_{P G U, t}+e d_{B S, t} \times \eta_{d, B S}+e f_{C S, B, t} \\
= & E L_{t}+e f_{B, G, t}+\frac{e c_{B D, t}}{\eta_{C, B S}}+e f_{B, C S, t} \forall t
\end{aligned}
$$

The energy providers are limited. The grid needs power plants (fossil fuel or renewable power plant) to provide energy to the demand side of the grid.

\section{Storage}

The storage system of the grid is one of the most important parts. Charge and discharge functions in the EVs and the batteries in the charging stations are the base duty of the vehicle to grid (V2G) and grid to vehicle (G2V) services. Storage systems should be placed in safe and more usable locations such as gas stations so that it may be economical and safe. For example, vanadium redox flow batteries can be placed in gas stations and they can support fast charge systems [32]. A PV based charging station with power forecasting capabilities designed for Ankara city, Turkey has been demonstrated previously. Such technologies may improve the grid infrastructure to provide wide options for EV users. Some other storage systems may use certain places and mobile charging stations. Mobile charging stations can help the grid when the grid support overloads of EVs. They should be made by ultra-capacitor and lithium batteries such as LiTiO/ $\mathrm{NiMnO}_{2}$ and $\mathrm{LiFePO}_{4}$ [29]. Storage systems in the grid are distributed and need to be controlled accurately. Control systems must control other distributed small-scale control systems [30]. For example, in the case study with $C_{6} /$ $\mathrm{LiNiCOAIO}_{2}$ type battery used in grid side (home or office), the cell temperature of batteries can be calculated by [33]:

$$
m c_{p} \frac{d}{d t} T_{(t)}+h A\left[T_{(t)}-T_{a m b}\right]=I\left(V-V_{o c}\right)
$$

Where, $m$ is cell mass to the unit gram, $c_{p}$ is cell heat capacity in joule per kilogram kelvin, $T$ is battery bulk temperature in kelvin, $h$ is heat transfer coefficient in watt per square meter, $A$ is cell surface area, and $T_{a m b}$ is ambient temperature. Temperature is one of the important factors influencing degradation. However, capacity fade and power fade also cause battery degradation. Both of them can be calculate by [33]:

$$
\begin{aligned}
& C F=1-\frac{Q-\mu_{C F} Q_{\text {rated }}}{Q_{\text {rated }}-\mu_{C F} Q_{\text {rated }}} \\
& P F=\frac{1}{\mu_{P F}}\left(\frac{R_{0}+R_{1}}{R_{0}(0)+R_{1}(0)}-1\right)
\end{aligned}
$$

Where, $P F$ is power fade, $C F$ is capacity fade, $Q$ is cell capacity, $Q_{\text {rated }}$ is the maximum discharge capacity defined by manufacturer, $\mu_{C F}$ is factor of the cells' rated capacity, $\mu_{P F}$ is factor of the cells' total resistance. Fig 3 gives the battery Thevenin model.

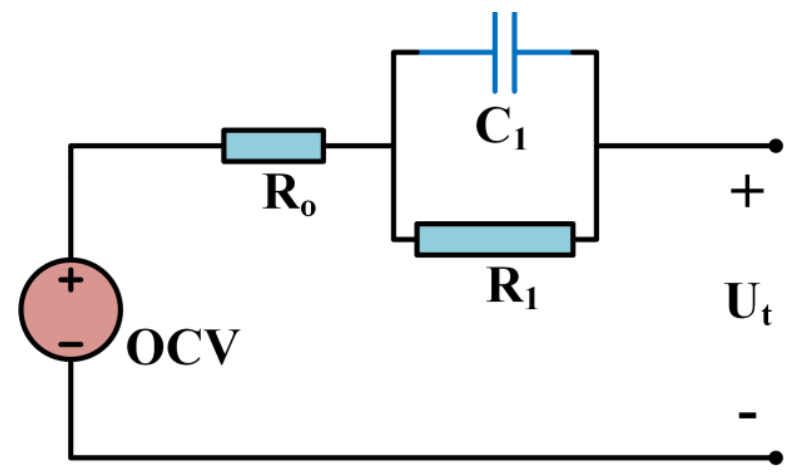

Fig 3: Thevenin equivalent model of battery [33].

In addition, cost of the battery degradation can be calculated by [33]:

$$
\begin{array}{r}
£_{\text {deg }}=\max \left[C F \times £_{\text {batt }}, P F\right. \\
\left.\times £_{\text {batt }}\right]
\end{array}
$$


INTERNATIONAL JOURNAL of SMART GRID, ijSmartGrid

T. Harighi et al. ,Vol. 2, No. 1, March, 2018

All of the mentioned issues are related to the battery life but the usage method of the batteries is alos important, as they set the battery performance while using them all together on the grid. The battery management system must follow the battery statement according to the SOC. SOC estimation should consider some other parameters such as thermal and mechanical effects on the storage system since all of them are effective parameters. SOC of the battery is the ratio of battery energy consumption and voltage of the battery. Relationship of the battery SOC and battery voltage curve can be determined by some tests on the battery with some battery test machine in a limited number of cycles (0-1000). SOC conditions in charge/discharge mode and open circuit mode are different. Fig 4 shows the difference between (a) voltage / SOC and (b) charging/discharging and open circuit voltage [34].

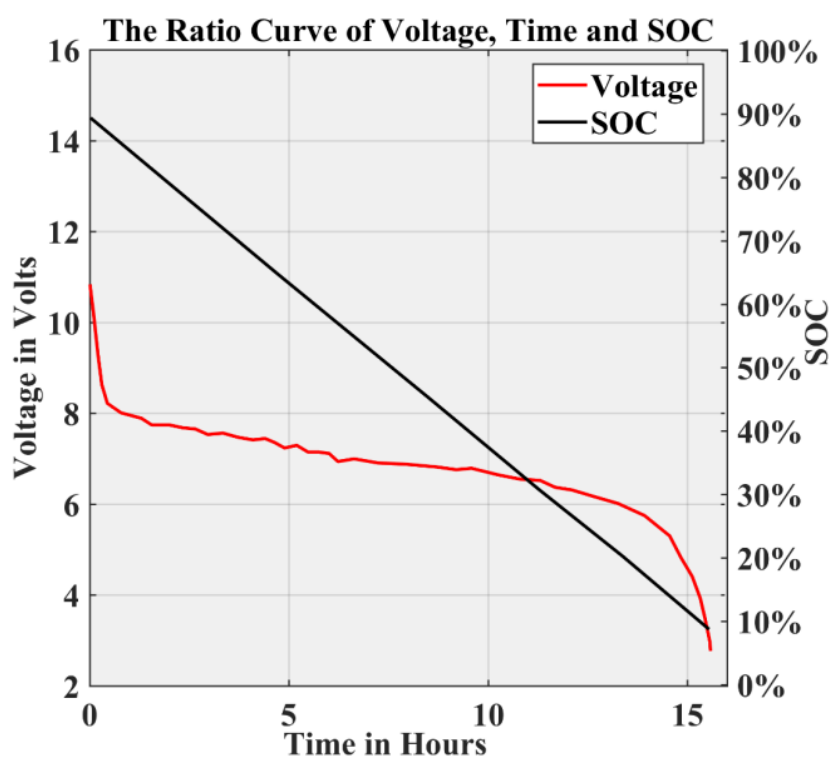

(a)

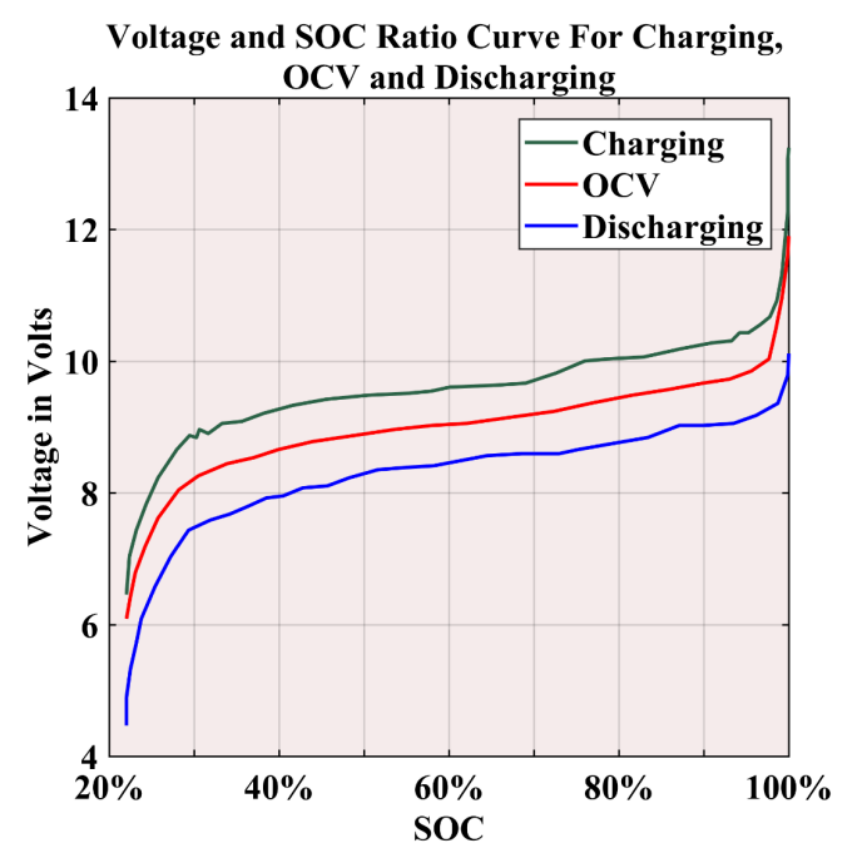

(b)

Fig 4: (a) Voltage, time and SOC ratio curve: SOC decrease follows a straight line, whereas the voltage stays almost constant over maximum part of the range; (b) voltage and SOC ratio curve in charging, OCV and discharging mode: the graphs are identical for these three scenarios - charging voltage having the highest value, and discharging voltage having the lowest.

All SOC estimation algorithms have error ratios and they change between 1\% 5\%. Extended Kalman filter (EKF) with $\leq 1 \%$, genetic algorithms (GA) with $\leq 2 \%$ and bi-linear interpolation (bi) with $\leq 5 \%$ are algorithms error tested on the LiFePO4 storage. EKF algorithm is very accurate for estimating targets depending on input data quality, so EKF is an algorithm to find the correct target by target prediction and measurement [35]. Also this algorithm is used in aircraft and aircraft detection radars to follow targets, it means that the EKF algorithm is one of the best target following system for users. In SOC estimation, case the OCV and current of circuit can be calculated from:

Kirchhoff's law:

$$
\begin{aligned}
& U_{O C V}=U_{T}+i_{L} R_{O}+U_{1} \\
& i_{L}=C_{1} \frac{d U_{1}}{d t}+\frac{U_{1}}{R_{1}}
\end{aligned}
$$

Laplace transform:

$$
\begin{aligned}
& i_{L}=C_{1} s U_{1}(S)+\frac{1}{R_{1}} U_{1}(S) \\
& U_{1}(s)=i_{L}(s) \cdot \frac{R_{1}}{1+R_{1} C_{1} s} \\
& U_{O C V}(s)-U_{t}(s)=i_{L}(s) \cdot\left(R_{0}+\frac{R_{1}}{1+R_{1} C_{1} s}\right)
\end{aligned}
$$

Bilinear transform: 


$$
S=\frac{2}{T} \cdot \frac{1-z^{-1}}{1+z^{-1}}
$$

$$
\begin{aligned}
& U_{O C V}\left(z^{-1}\right)-U_{t}\left(z^{-1}\right)= \\
& i_{L}\left(z^{-1}\right) . \frac{\frac{R_{0} T+R_{1} T+2 R_{0} R_{1} C_{1}}{T+2 R_{1} C_{1}}+\frac{R_{0} T+R_{1} T+2 R_{0} R_{1} C_{1}}{T+2 R_{1} C_{1}} Z-1}{1+\frac{T-2 R_{1} C_{1}}{T+2 R_{1} C_{1}} Z-1}
\end{aligned}
$$

Inverse Z-transform:

To simplify the equations, let us consider the following parameters:

$$
\begin{aligned}
& a_{1}=-\frac{T-2 R_{1} C_{1}}{T+2 R_{1} C_{1}} \\
& a_{2}=-\frac{R_{0} T+R_{1} T+2 R_{0} R_{1} C_{1}}{T+2 R_{1} C_{1}} \\
& a_{3}=-\frac{R_{0} T+R_{1} T-2 R_{0} R_{1} C_{1}}{T+2 R_{1} C_{1}} \\
& U_{t}(k)=U_{O C V}(k)-a_{1} U_{O C V}(k-1)+a_{1} U_{t}(k-1)+ \\
& a_{2} i_{L}(k)+a_{3} i_{L}(k-1) \\
& M(k)=U_{O C V}(k)-a_{1} U_{O C V}(k-1) \\
& U_{t}(k)=M(k)+a_{1} U_{t}(k-1)+a_{2} i_{L}(k)+a_{3} i_{L}(k-1)
\end{aligned}
$$

If transformed into vector notation:

$$
\begin{aligned}
& \varphi(k)=\left[1 U_{t}(k-1) i_{L}(k) i_{L}(k-1)\right. \text { and } \\
& \theta(k)=\left[M(k) a_{1} a_{2} a_{3}\right]^{T} \\
& U_{t}(k)=\varphi(k) \theta(k)
\end{aligned}
$$

Mentioned methods are to achieve OCV and SOC curve in battery Thevenin model. Some other algorithms such as recursive least squares (RLS) and least mean square (LMS) may optimize Thevenin model calculation. Also some methods improve both RLS and LMS algorithms. All of the improvement methods are created to reduce base algorithms such as EKF error rate. According to context, the storage systems must be powerful and the control systems should have full access. The storage systems work properly when they are designed with proper parameters, and sound understanding of the whole system.

\section{Environmental Issue}

Site selection and modeling of grid depends on environmental conditions, as these are different in each location [31]. For example, the environment of Iran is the same as Turkey but environmental conditions of Alaska or Siberia is different from Turkey and Iran. Priority of some factors changes by environmental location. Weather, the flatness of area, shape of the buildings in an area and such cases play vital roles in choosing EV charging station architectures [36]. In some cases, the area has a low density of population, which is an ideal condition. So, the management of grid has time to respond to the EV load. However, in most cases, the grid needs power immediately, and energy generators such as renewable energy or CHP should be added quickly. In different locations, it can be determined by highspeed communication systems, such as long-term evolution (LTE). Because of diverse EV battery status and number of charging stations, information must be stored in certain databases to help EV users and grid management [37]. Calculation and prediction of charge status are very easy even without GPS signal or related equipment and it can be transmitted by some telecommunication equipment. It can be calculated with speed and time parameters in comparison to the previous charging station in the trajectory [38]:

$v_{j}\left(t_{i}, \operatorname{link}_{i}\right)=\left\{\begin{array}{cc}\sum_{k=1}^{N} \frac{v_{k}\left(t_{i} \pm \Delta_{t}, l_{i n k_{i}}\right)}{N} & \text { if } N>1 \\ v_{j}\left(t_{i-1}, \operatorname{link}_{i-1}\right) & \text { if } N=1\end{array}\right.$

Here $\mathrm{N}$ is the number of EVs that are temporary in a selected charging station during the time break, $v_{j}\left(t_{i}, \operatorname{link}_{i}\right)$ is the speed of the $j-t h$ vehicle at time $t_{i}$ in the station $\operatorname{link}_{i}$. It relates to infrastructural issues. For example, an area with unevenness needs more power and charging station than a more even area. In fact, the environmental conditions determine our grid model and charging station locations [38]. Environmental analysis should be done carefully. Potential of location from each side of the grid (supply/demand) depends on environment conditions such as: weather, structure of the buildings, terrain, potential of renewable energy, electrification of location, and available communication technology.

\section{Budget}

The budget of each project is an important motivation. But the project provision of the budget may happen in two ways. In some projects, it may happen before project initiation. But in some others, it may happen over a short/long time after the project starts. Electric fleet systems need a big budget and it should be supplied before the start of project and provision of project budget will happen after short/long time that depends on the economic condition of the area [39]. The profile of the conception in each location is different from other locations and each has a typical profile. Usage algorithm of some areas is achieved by those profiles [40]. Priority of some factors depends on the custom of location. The budget profiles are calculated by usage pattern in downtown/urban/suburb, infrastructure of grid, and environmental condition. Usage pattern has an influence on energy consumption of the area. For example, people of the Middle East use energy more than the people of EU or Asia. However, according to the environmental condition in the Middle East, the usage should be less. In fact, low price of petrol had a bad influence on the consumption culture; which is used to be the same in the US in the past. 
INTERNATIONAL JOURNAL of SMART GRID, ijSmartGrid

T. Harighi et al. ,Vol. 2, No. 1, March, 2018

The infrastructure of the grid should be upgraded with the least number of converters and loss, as the energy loss in the grid is against the budget. Some governments save money by decreasing energy loss and some governments spend money to decrease energy loss [41]. Finally, the governments should offer some profitable plans to the investors, as the investors determine which projects are economical and which ones are not.

\section{Summary}

All of the mentioned issues are considered to protect grid and produce high-quality electric power. However, those are just some threats when the grid supplies EVs in a certain location. In one of the MATLAB examples provided in its official website (24-hour Simulation of a Vehicle-to-Grid (V2G) System), by adjusting the number of cars (2 times more than original quantity), results of "Load, active load and reactive load" curves are observed to change as shown in Fig 5. It gives load curve from 1 2 seconds on the grid. They show unexpected incremental behavior in load curve from $9.7^{*} 10^{\wedge} 6$ to $11.8^{*} 10^{\wedge} 6$. Load increase/decrease needs more/less power supply when the quantity of cars is changed. It may affect the electric power quality in negative direction.

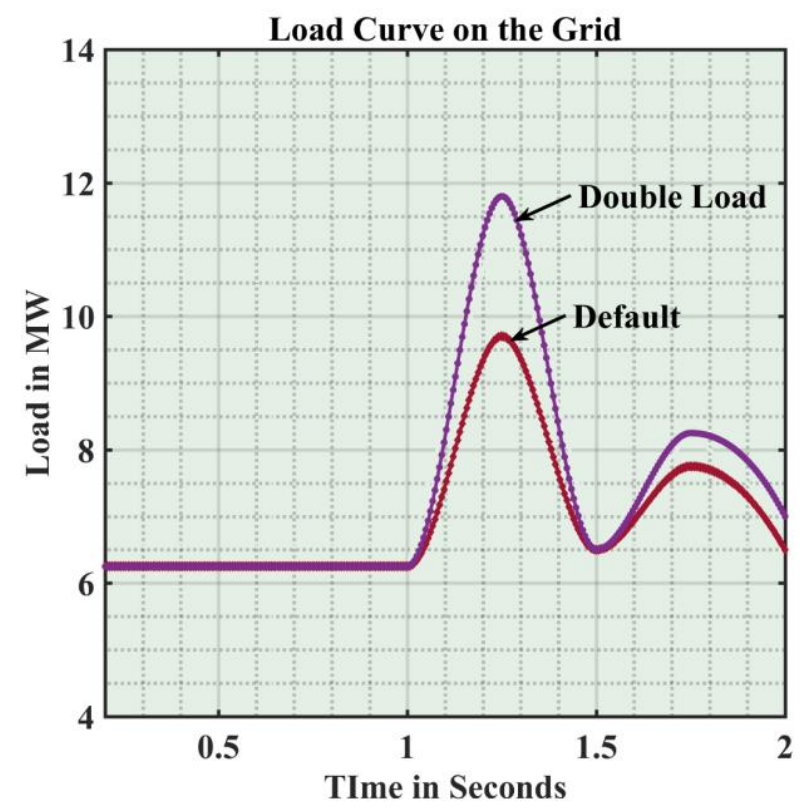

Fig 5: Load after and before adjustment of quantity of cars. The amount of $9.7^{*} 10^{\wedge} 6$ rose to $11.8^{*} 10^{\wedge} 6$.

Fig 6 shows active power load of the grid in unexpected decrement (1 2 seconds). The active power load at the beginning decreases from $2.9 * 10^{\wedge} 6$ in the first situation to $0.9^{*} 10^{\wedge} 6$ in the second situation. After this increase, in the second curve, active power increases from $7.3^{*} 10^{\wedge} 6$ in the first situation to $8^{*} 10^{\wedge} 6$ in the second situation. The negative impact in the second situation is harder than in the first situation. It may reinforce protection error and reduce power quality. So the grid needs power balance when the EV quantity is increased or decreased. Sometimes it may cause errors in the grid.
Fig 7 gives reactive power during sudden change. Difference between first and second state is that the sudden ups and downs are increased in the second state. Sudden up and down in reactive curve reduce grid safety, therefore protection system in the grid must be prepared for these changes. In this situation, the grid protection system automatically removes some safety procedures and some real errors. Those problems influence grid responsibility.

The curves show that grid may be damaged and fail to protect in each unprecedented situation. Grid safety is in danger when the sudden ups and downs happen in the load curve.

The following conditions must be considered in the existing situation:

- Infrastructure equipment should have required ratings in switching and regulating condition. So the grid needs $800 \mathrm{~V} / 500 \mathrm{~V}$ DC line and 240V AC line with more power to support charging station equipment.

- All existing sources should be used in the grid, although the whole capacity of them should not be used because we need it to reach a balance. The goal is to use clean energy.

- The cycle of charge and discharge of EVs should be taught throughout the world because the future vehicles are the electric vehicles.

- Location and area condition must be analyzed by grid designers to provide efficient energy.

The budget delivery schedule should be calculated accurately for encouragement.

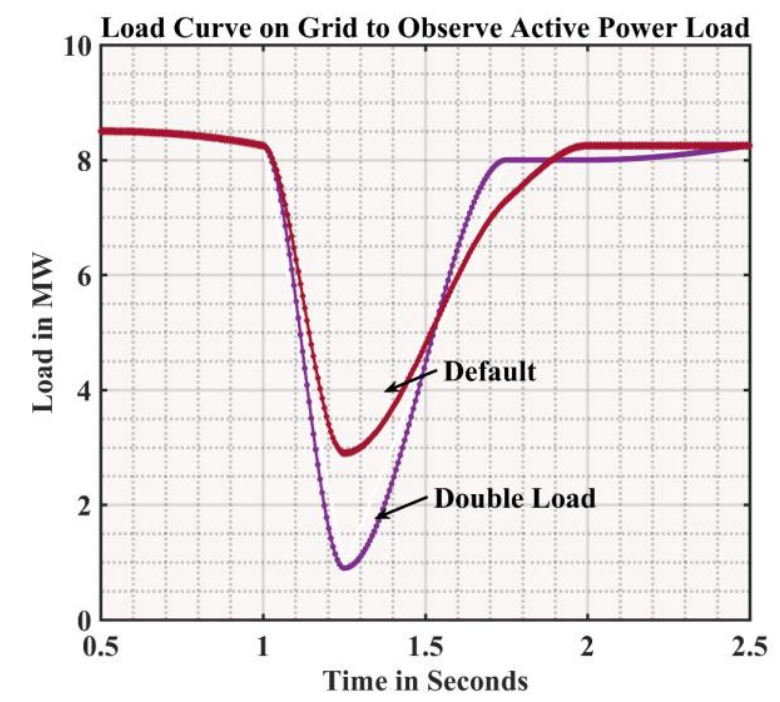

Fig 6: Active load after and before adjustment of quantity of cars. 


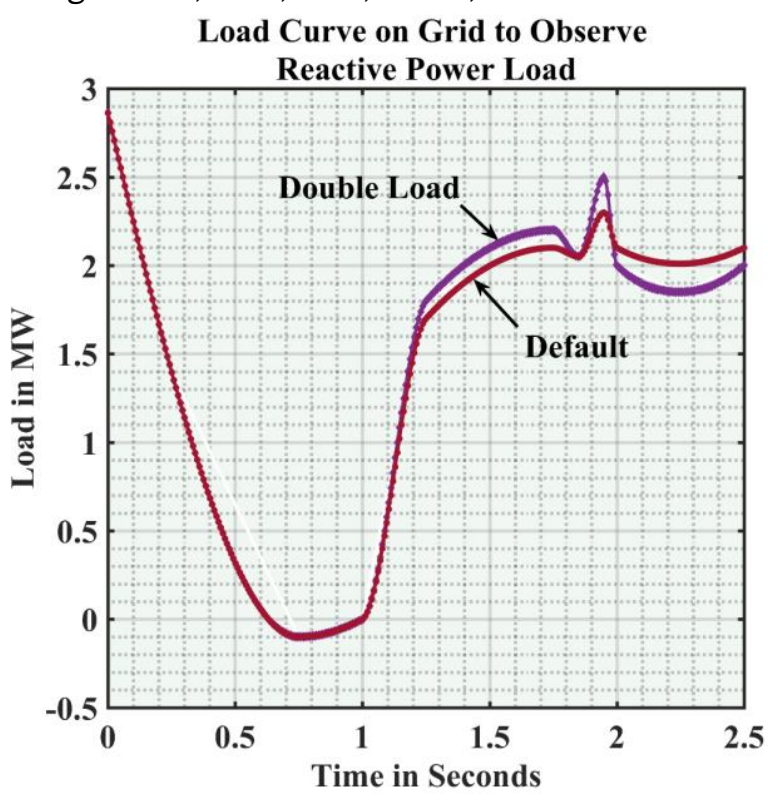

Fig 7: Reactive power after and before of the cars' quantity is adjusted.

\section{Conclusion}

Uncertainty of data and algorithms with errors can lead the grid to crises or undesirable condition. EVs in the grid and other customers have the same reaction in some conditions and grid controllers should control the grid according to situations in the grid that can happen in the moment. In this paper, some base factors have been illustrated, which have ability to create instability in the grid. In order to do that, the infrastructural requirements, required supply system and policy outlines, suitable storage techniques, relevant environmental factors, and budget considerations have been discussed. Finally, the findings have been validated through MATLAB simulations.

\section{Acknowledgment}

This research is developed from paper named; "Overview of Quality of Service Evaluation of a Charging Station for Electric Vehicle" which is presented in Renewable Energy Research and Applications (ICRERA), 2017 IEEE 6th International Conference.

\section{REFERENCES}

[1] F. Un-Noor, S. Padmanaban, L. Mihet-Popa, M. Mollah and E. Hossain, "A Comprehensive Study of Key Electric Vehicle (EV) Components, Technologies, Challenges, Impacts, and Future Direction of Development," Energies, vol. 10, no. 8, 2017.
[2] U. E. P. Agency, "Combined Heat and Power (CHP) Partnership," U.S. Environmental Protection Agency, [Online]. Available: https://www.epa.gov/chp/what-chp.

[3] X.-H. Sun, T. Yamamoto and T. Morikawa, "Fastcharging station choice behavior among battery electric vehicle users," Transportation Research Part D, vol. 46, pp. 26-39, 2016.

[4] Z.-H. Zhu, Z.-Y. Gaoa, J.-F. Zheng and H.-M. Dua, "Charging station location problem of plug-in electric vehicles," Journal of Transport Geography, vol. 52, pp. 11-22, 2016.

[5] S. Böll, "AUTO," spiegel, 0810 2016. [Online]. Available:

http://www.spiegel.de/auto/aktuell/bundeslaenderwollen-benzin-und-dieselautos-ab-2030-verbieten-a1115671.html. [Accessed 0810 2016].

[6] N. Shahraki, H. Cai, M. Turkay and M. Xu, "Optimal locations of electric public charging stations using real world vehicle travel patterns," Transportation Research Part D, vol. 41, pp. 165-176, 2015.

[7] J. Kim, S.-Y. Son, J.-M. Lee and H.-T. Ha, "Scheduling and performance analysis under a stochastic model for electric vehicle charging stations," Omega, vol. 66, pp. 278-289, 2017.

[8] H. Cai, X. Jia, A. S. Chiu, X. Hue and M. Xu, "Siting public electric vehicle charging stations in Beijing using big-data informed travel patterns of the taxi fleet," Transportation Research Part D, vol. 33, pp. 39-46, 2014.

[9] D. Wellisch, J. Lenz, A. Faschingbauer and S. K. R. Pöschl, "Vehicle-to-Grid AC Charging Station: An Approach for Smart Charging Development," IFAC, Vols. 48-4, pp. 55-60, 2015.

[10] T. Harighi, R. Bayindir and E. Hossain, "Overview of Quality of Service Evaluation of a Charging Station for Electric Vehicle," 2017 IEEE 6th International Conference on Renewable Energy Research and Applications (ICRERA), no. EV, pp. 1180-1185, 2017.

[11] T. Harighi, R. Bayindir and E. Hossain, "Overview of quality of service evaluation of a charging station for electric vehicle," in Renewable Energy Research and Applications (ICRERA), 2017 IEEE 6th International Conference on, San Diego, CA, USA, 2017. 
T. Harighi et al. ,Vol. 2, No. 1, March, 2018

[12] P. García-Trivino, J. P. Torreglosa, L. M. FernandezRamírez and F. J. c, "Control and operation of power sources in a medium-voltage directcurrent microgrid for an electric vehicle fast charging station with a photovoltaic and a battery energy storage system," energy, vol. 115, no. energy, pp. 38-48, 2016.

[13] C. Capassoa, D. Iannuzzib and O. Veneria, "DC Charging Station for Electric and Plug-In Vehicles," Energy Procedia, vol. 61, pp. 1126-1129, 2014.

[14] I. Zenginis, J. S. Vardakas, N. Zorba and C. V. Verikoukis, "Analysis and quality of service evaluation of a fast charging station for electric Vehicles," Energy, vol. 112, no. energy, pp. 669-678, 2016.

[15] Q. Wang, N. Zhou, J. Wang and N. Wei, "Harmonic amplification investigation and calculation of electric vehicle charging stations using three-phase uncontrolled rectification chargers," Electric Power Systems Research, vol. 123, pp. 174-184, 2015.

[16] J. P. Torreglosa, P. García-Triviño, L. M. FernándezRamirez and F. Jurado, "Decentralized energy management strategy based on predictive controllers for a medium voltage direct current photovoltaic electric vehicle charging station," Energy Conversion and Management, vol. 108, no. Energy, pp. 1-13, 2016.

[17] S. Shojaabadi, S. Abapour, M. Abapour and A. Nahavandi, "Simultaneous planning of plug-in hybrid electric vehicle charging stations and wind power generation in distribution networks considering uncertainties," Renewable Energy, vol. 99, no. Energy, pp. 237-252, 2016.

[18] J. Y. Yong, V. K. Ramachandaramurthy, K. M. Tan and N. Mithulananthan, "Bi-directional electric vehicle fast charging station with novel reactive power compensation for voltage regulation," Electrical Power and Energy Systems, vol. 64, no. Energy, pp. 300-310, 2015.

[19] H. Fathabadi, "Novel grid-connected solar/wind powered electric vehicle charging station with vehicle-to-grid technology," Energy, vol. 132, pp. 1-11, 2017.

[20] F. Sanchez-Sutila, J. Hernándeza and C. Tobajas, "Overview of electrical protection requirements for integration of a smart DC node with bidirectional electric vehicle charging stations into existing AC and DC railway grids," Electric Power Systems Research, vol. 122, no. energy, pp. 104-118, 2015.
[21] C. Capasso and O. Veneri, "Experimental study of a DC charging station for full electric and plug in hybrid vehicles," Applied Energy, vol. 152, pp. 131-142, 2015.

[22] O. Hafez and K. Bhattacharya, "Optimal design of electric vehicle charging stations considering various energy resources various energy resources," Renewable Energy, vol. 107, pp. 576-589, 2017.

[23] S. Suganya, S. C. Raja and P. Venkatesh, "Simultaneous coordination of distinct plug-in Hybrid Electric Vehicle charging stations: A modified Particle Swarm Optimization approach," energy, vol. 138, pp. 92-102, 2017.

[24] Z. Xua, K. Youa and C. Zhangb, "Analytical Models of Power Losses of a Three phase AC-DC Rectifier for Hybrid Electric Vehicles," CUE2015-Applied Energy Symposium and Summit 2015: Low carbon cities and urban energy systems, vol. 88, pp. 978-984, 2016.

[25] Y. Kuang, Y. Chen, M. Hua and D. Yang, "Influence analysis of driver behavior and building category on economic performance of electric vehicle to grid and building integration," Applied Energy, no. energy, 2017.

[26] P. Fekete, S. Lim, S. Martin, K. Kuhn and N. Wright, "Improved energy supply for non-road electric vehicles by occasional charging station location modelling," Energy, vol. 114, pp. 1033-1040, 2016.

[27] G. C. Mouli, P. Bauer and M. Zeman, "System design for a solar powered electric vehicle charging station for workplaces," Applied Energy, vol. 168, no. energy, pp. 434-443, 2016.

[28] Y. Motoaki and M. G. Shirk, "Consumer behavioral adaption in EV fast charging through pricing," Energy policy, vol. 108, pp. 178-183, 2017.

[29] T. D. Atmajaa and Amina, "Energy storage system using battery and ultracapacitor on mobile charging station for electric vehicle," 2nd International Conference on Sustainable Energy Engineering and Application, ICSEEA 2014, vol. 68, no. Energy, pp. 429-437, 2015.

[30] M. Bayati, M. Abedi, H. Hosseinian and G. B. Gharehpetian, "A novel control strategy for Reflex-based electric vehicle charging station with grid support functionality," Journal of Energy Storage, vol. 12, no. Storage, pp. 108-120, 2017.

[31] C. G. Cassandras and Y. Geng, "Optimal Dynamic 
INTERNATIONAL JOURNAL of SMART GRID, ijSmartGrid

T. Harighi et al. ,Vol. 2, No. 1, March, 2018

Allocation and Space Reservation for Electric Vehicles at Charging Stations," Proceedings of the 19th World Congress The International Federation of Automatic Control Cape Town, South Africa. August 24-29, 2014, vol. 19, pp. 4056-4061, 2014.

[32] A. Cunha, F. Brito, J. Martins, N. Rodrigues, V. Monteiro, J. L. Afonso and P. Ferreira, "Assessment of the use of vanadium redox flow batteries for energy storage and fast charging of electric vehicles in gas stations," Energy, vol. 115, no. Energy, pp. 1478-1494, 2016.

[33] U. Kotub, J. Tim, W. Widanalage, C. Gael, J. Paul and M. James, "On the possibility of extending the lifetime of lithium-ion batteries through optimal V2G facilitated by an integrated vehicle and smart grid system," Energy, no. Energy, pp. 710-722, 2017.

[34] I. N. Haq, R. H. Saputra, F. Edison, D. Kurniadi, E. Leksono and B. Yuliarto, "State of Charge (SoC) Estimation of LiFePO4 Battery Module Using Support Vector Regression," in Joint International Conference on Electric Vehicular Technology and Industrial, Mechanical, Electrical and Chemical Engineering (ICEVT \& IMECE) 2015, 2015.

[35] M. Hannan, M. Lipu, A. Hussain and A. Mohamed, "A review of lithium-ion battery state of charge estimation and management system in electric vehicle applications: Challenges and recommendations," Renewable and Sustainable Energy Reviews, vol. 78, no. battery, pp. 834-854, 2017.

[36] S. Alegre, J. V. Míguez and J. Carpio, "Modelling of electric and parallel-hybrid electric vehicle using Matlab/Simulink environment and planning of charging stations through a geographic information system and genetic algorithms," Renewable and Sustainable Energy Reviews, vol. 74, pp. 1020-1027, 2017.

[37] C. Liu, Q. Zhou, J. Hu, H. Xu and H. Zhang, "Modelling and Simulation of centralized electric vehicle charging station wireless communication networks," International Conference on Advances in Computational Modeling and Simulation, vol. 31, pp. 746-750, 2012.

[38] N. Andrenacci, R. Ragona and G. Valenti, "A demandside approach to the optimal deployment of electric vehicle charging stations in metropolitan areas," Applied Energy, vol. 182, pp. 39-46, 2016.

[39] R. J. Flores, B. P. Shaffer and J. Brouwer, "Electricity costs for an electric vehicle fueling station with Level 3 charging," Applied Energy, vol. 169, pp. 813-830, 2016.

[40] Y. Xiang, J. Liu, R. Li, F. Li, C. Gu and S. Tang, "Economic planning of electric vehicle charging stations considering traffic constraints and load profile templates," Applied Energy, vol. 178, pp. 647-659, 2016.

[41] Y. A. Alhazmi and M. M. Salamab, "Economical staging plan for implementing electric vehicle charging stations," Sustainable Energy, Grids and Networks, vol. 10, pp. 1225, 2017. 